\title{
ИНСТРУМЕНТЫ СТИМУЛИРОВАНИЯ ИНВЕСТИЦИОННОЙ АКТИВНОСТИ В СЕЛЬСКОМ ХОЗЯЙСТВЕ (НА ПРИМЕРЕ РОСТОВСКОЙ ОБЛАСТИ)
}

\section{INSTRUMENTS FOR STIMULATING INVESTMENT ACTIVITY IN AGRICULTURE (ON THE EXAMPLE OF THE ROSTOV REGION)}

A. Brik

G. Plohotnikova

Summary: The article analyzes the dynamics of the gross regional product of the Rostov region for the period 2016-2018, the main indicators of agricultural development, substantiates the tools aimed at stimulating the investment activity of agricultural producers at the mesoeconomic level. The results of the study can be used by the state authorities of the Russian Federation and the constituent entities of the Russian Federation in the development of strategic planning documents, as well as by economic entities carrying out investment activities at the regional level.

Keywords: region, Rostov region, regional economy, agriculture, incentives, gross regional product.

Брик Анна Дмитриевна

К.ю.н., дочент, ФГБОУВО «Донской государственный аграрный университет», n. Персиановский

brikad@mail.ru

Плохотникова Галина Владимировна

К.э.н., дочент, Новочеркасский инженерномелиоративный институт им. А.К. Кортунова филиал ФГБОУ ВО «Донской государственный аграрный университет", г. Новочеркасск g409zx@yandex.ru

Аннотация: В статье анализируются динамика валового регионального продукта Ростовской области за период 2016-2018 гг, основные показатели развития сельского хозяйства, обосновываются инструменты, направленные на стимулирование инвестиционной активности сельскохозяйственных товаропроизводителей на мезоэкономическом уровне. Результаты исследования могут использоваться органами государственной власти РФ и субъектов РФ при разработке документов стратегического планирования, а также хозяйствующими субъектами, осуществляющими инвестиционную деятельность на региональном уровне.

Ключевые слова: регион, Ростовская область, региональная экономика, сельское хозяйство, стимулирование, валовой региональный продукт.

рицательная динамика доли АПК в структуре ВРП (с 12,4 \% в 2016 г. до 10,2 \% в 2018 г.). В абсолютных значениях снижение составило 11603,8 млн руб. Тем не менее, в силу территориальных, природно-климатических особенностей Ростовской области, агпропромышленный комплекс является основным работодателем для граждан, проживающих в 29 из 55 муниципальных образований региона $[3,8]$.

В таблице 2 представлена информация, характеризующая показатели развития сельского хозяйства Ростовской области за 2016-2018 гг [5].

Согласно информации, отражённой в таблице 2, в регионе наблюдается положительная динамика посевных площадей возделываемых сельхозкультур. Указанный показатель увеличился с 4528,7 тыс. га до 4641,0 тыс. га (+112,3 тыс. га) за период наблюдения. Посевные площади наиболее выгодных культур - зерновых и зернобобовых, подсолнечника возросли на 202,3 тыс. га и 118,9 тыс. га соответственно. Однако, несмотря на рост посевных площадей, валовой сбор зерна упал за период наблюдения 744,8 тыс. т. По указанному показателю Ростовская область занимает 2-е место среди субъектов Российской Федерации, уступая лишь Краснодарскому краю. 
Таблица 1.

Динамика валового регионального продукта Ростовской области за период 2016-2018 гг, млн руб.

\begin{tabular}{|c|c|c|c|c|}
\hline Наименование показателя & 2016 г. & 2017 г. & 2018 г. & Динамика \\
\hline Агропромышленный комплекс & 159405,2 & 143505,1 & 147801,4 & $-11603,8$ \\
\hline Использование недр & 11152,7 & 16117,2 & 17081,9 & 5929,2 \\
\hline Промышленное производство & 254961,5 & 277817,7 & 300967,4 & 46006,0 \\
\hline Производство электрической и тепловой энергии, газоснабжение & 57700,7 & 59226,5 & 64892,6 & 7191,9 \\
\hline $\begin{array}{l}\text { Водоснабжение и водоотведение, утилизация отходов производ- } \\
\text { ства и потребления }\end{array}$ & 10620,8 & 12162,9 & 14365,1 & 3744,2 \\
\hline Строительная деятельность & 97840,8 & 104684,8 & 82191,1 & $-15649,7$ \\
\hline Торгово-закупочная деятельность & 232122,6 & 240574,3 & 255482,9 & 23360,3 \\
\hline Оказание логистических услуг & 87550,6 & 96528,7 & 112492,7 & 24942,1 \\
\hline Оказание гостиничных услуг & 15986,7 & 17239,5 & 19012,6 & 3025,9 \\
\hline Оказание телекоммуникационных услуг & 26787,3 & 28836,7 & 32375,4 & 5588,2 \\
\hline Оказание финансовых и страховых услуг & 2830,7 & 2551,3 & 3864,4 & 1033,6 \\
\hline Операции с недвижимостью & 96866,3 & 105881,1 & 117748,7 & 20882,5 \\
\hline $\begin{array}{l}\text { Научно-исследовательская и опытно-конструкторская деятель- } \\
\text { ность }\end{array}$ & 36530,1 & 37452,5 & 40924,7 & 4394,6 \\
\hline Предоставление государственных и муниципальных услуг & 21882,3 & 22120,9 & 24776,7 & 2894,4 \\
\hline Предоставление социальных услуг & 62405,8 & 64789,6 & 69500,1 & 7094,4 \\
\hline Услуги в сфере образования & 38075,1 & 46386,5 & 51296,7 & 13221,6 \\
\hline Предоставление услуг в сфере здравоохранения & 56534,5 & 61703,1 & 74259,4 & 17725,0 \\
\hline $\begin{array}{l}\text { Предоставление услуг в сфере физической культуры и спорта, ор- } \\
\text { ганизация досуга }\end{array}$ & 6921,3 & 7449,2 & 9314,3 & 2393,0 \\
\hline Иные виды экономической деятельности & 7573,1 & 7294,2 & 7878,4 & 305,3 \\
\hline Bсего & 1283748,1 & 1352321,9 & 1446226,6 & 162478,5 \\
\hline
\end{tabular}

Основные показатели развития сельского хозяйства Ростовской области

Таблица 2. за период 2016-2018 гг. по всем категориям хозяйств

\begin{tabular}{|c|c|c|c|c|}
\hline Показатель & 2016 г. & 2017 г. & 2018 г. & Динамика \\
\hline $\begin{array}{l}\text { посевные площади возделываемых в регионе сельхоз культур, } \\
\text { тыс. га., в т. ч. }\end{array}$ & 4528,7 & 4538,1 & 4641,0 & 112,3 \\
\hline - сахарной свёклы & 18,4 & 19,7 & 22,5 & 4,1 \\
\hline - подсолнечника & 594,7 & 714,9 & 713,6 & 118,9 \\
\hline - зерновых и зернобобовых & 3297,2 & 3380,2 & 3499,5 & 202,3 \\
\hline - овощей & 27,3 & 26,2 & 25,2 & $-2,1$ \\
\hline - картофеля & 17,2 & 16,9 & 16,7 & $-0,5$ \\
\hline - другие культуры & 573,9 & 380,2 & 363,5 & $-210,4$ \\
\hline \multicolumn{5}{|c|}{ Валовые сборы возделываемых в регионе сельхозкультур, тыс. т } \\
\hline - сахарной свёклы & 1001,0 & 860,9 & 687,2 & $-313,8$ \\
\hline - подсолнечника, & 1261,2 & 1429,5 & 1341,1 & 79,9 \\
\hline - зерна (в весе после доработки) & 11656,4 & 13459,6 & 10911,6 & $-744,8$ \\
\hline - овощей & 582,1 & 597,2 & 521,7 & $-60,4$ \\
\hline - картофеля & 265,9 & 309,5 & 338,9 & 73,0 \\
\hline
\end{tabular}


Производство сельскохозяйственной продукции за период 2016-2018 гг

(в хозяйствах всех категорий; в фактических ценах)

\begin{tabular}{|l|c|c|c|c|c|c|c|c|}
\multirow{2}{*}{ Показатель } & \multicolumn{2}{|c|}{2016 г. } & \multicolumn{2}{c|}{2017 г. } & \multicolumn{2}{c|}{2018 г. } & \multicolumn{2}{c|}{ Динамика } \\
\cline { 2 - 10 } & Млн руб. & $\%$ & Млн руб. & $\%$ & Млн руб. & $\%$ & Млн руб. & $\%$ \\
\hline РФ в целом & 5112356 & 100 & 5109475 & 100 & 5348777 & 100 & 236421 & - \\
\hline Ростовская область & 252777 & 4,94 & 254431 & 4,98 & 255129 & 4,77 & 2352 & $-0,17$ \\
\hline
\end{tabular}

Таблица 4.

Сальдированный финансовый результат* сельскохозяйственных товаропроизводителей Ростовской области за период 2016-2018 гг, млн руб.

\begin{tabular}{|l|c|c|c|c|}
\hline Направление сельскохозяйственного производства & 2016 г. & 2017 г. & 2018 г. & Динамика \\
\hline Животноводство & -1920 & -4522 & -12691 & -10771 \\
\hline Растениеводство & 10523 & 5619 & 8386 & -2137 \\
\hline
\end{tabular}

Примечание: сальдированный финансовый результат рассчитывается как прибыль минус убыток.

Таблица 5.

Действующие нормативно-правовые документы Ростовской области, направленные

на стимулирование инвестиционной активности сельскохозяйственных товаропроизводителей.

Наименование Постановления Правительства Ростовской области

№377 от 25 мая 2017 г. «0 порядке предоставления субсидий сельскохозяйственным товаропроизводителям (кроме граждан, ведущих личное подсобное хозяйство) на возмещение части затрат на текущий ремонт и планировку оросительных систем, расчистку коллекторно-дренажной сети, приобретение и доставку фосфогипса, приобретение гербицидов, ленты капельного орошения, необходимого оборудования и специализированной техники для удаления сорной растительности на мелиоративных каналах (с изменениями на 1 февраля 2019 года)»

№277 от 12 апреля 2012 г. «0 порядке предоставления субсидий сельскохозяйственным товаропроизводителям (кроме граждан, ведущих личное подсобное хозяйство) на возмещение части затрат на оплату услуг по подаче воды для орошения и затрат на оплату электроэнергии, потребляемой внутрихозяйственными насосными станциями при подаче воды для орошения сельскохозяйственных культур»

№107 от 16 февраля 2017 «0 порядке предоставления субсидий сельскохозяйственным товаропроизводителям (кроме граждан, ведущих личное подсобное хозяйство) на реализацию мероприятий в области мелиорации земель сельскохозяйственного назначения»

Краткое содержание документа
$\begin{aligned} & \text { Сельхозтоваропроизводителям, зарегистрированным в Ростовской обла- } \\ & \text { сти, из регионального бюджета выделяются субсидии на следующие цели: } \\ & \text { оплата работ, осуществлённых как собственными силами, так и с привле- } \\ & \text { чением контрагентов, в связи с текущем ремонтом, планировкой объектов } \\ & \text { оросительной инфраструктуры, обеспечением надлежащего функциониро- } \\ & \text { вания коллекторно-дренажной сети в текущем году; закупку лент капель- } \\ & \text { ного орошения } \\ & \text { Право на получение субсидии за счёт средств бюджетной системы РФ имеет } \\ & \text { сельхозтоваропроизводитель, зарегистрированный в установленном по- } \\ & \text { рядке в соответствующем государственном Реестре }\end{aligned}$
$\begin{aligned} & \text { Сельхозтоваропроизводителям, зарегистрированным в Ростовской обла- } \\ & \text { сти, из регионального бюджета выделяются субсидии на следующие цели: } \\ & \text { - реализацию мелиоративных проектов различных видов, связанных с } \\ & \text { защитой сельхозугодий от негативного воздействия техногенных и при- } \\ & \text { родных факторов; } \\ & \text { - реализацию проектов по строительству, реконструкции объектов ги- } \\ & \text { дротехнической инфраструктуры. }\end{aligned}$

Согласно информации, представленной в таблице 3, производство сельскохозяйственной продукции в стоимостном эквиваленте возросло за период наблюдения в Российской Федерации - на 236421 млн руб., в Ростовской области - на 2353 млн руб. В структуре сельхозпроизводства доля Ростовской области незначительно снизилась с 4,94 \% в 2016 г. до 4,77 \% в 2018 г. (-0,17\%). Финансовый результат сельхозтоваропроизводителей Ростовской области представлен в таблице 4. 
Как видно из информации, отражённой в таблице 4, хозяйствующие субъекты животноводческого и растениеводческого направления демонстрируют ухудшение финансовых результатов за период наблюдения. В частности, по направлению растениеводства снижение сальдированного финансового результата составило 2137 млн руб. (с 10523 млн руб. в 2016 г. до 8386 млн руб. в 2018 г.). При этом, необходимо акцентировать внимание на том, что в силу естественных природно-климатических факторов, направление животноводства в Ростовской области является убыточным на протяжении всего периода наблюдений. С учётом сказанного, представляется нецелесообразным широкомасштабная поддержка за счёт средств бюджетной системы РФ животноводческого производства в Ростовской области. В тоже время, усиление растениеводческого направления, в том числе за счёт мер государственного стимулирования, позволит укрепить конкурентоспособность региональной экономики, создать новые рабочие места, улучшить инвестиционную привлекательность сельского хозяйства Ростовской области.

В настоящее время в Ростовской области реализуются меры государственной поддержки хозяйствующих субъектов агропромышленного комплекса. В таблице 5 систематизированы действующие нормативно-правовые документы, направленные на стимулирование инвестиционной активности сельскохозяйственных товаропроизводителей.

Анализ содержания нормативно-правовых документов, регламентирующих механизм государственной поддержки сельскохозяйственных товаропроизводителей Ростовской области, позволяет говорить об акценте на развитие орошаемого земледелия.

Подводя итог сказанному, сформулируем следующие основные выводы:

1. Одним из важнейших региональных конкурентных преимуществ Ростовской области является совокупность природно-климатических и географических факторов, формирующих предпосылки для высокопродуктивной сельскохозяйственной деятельности в таких сферах, как растениеводство (главным образом, зерновое) и переработка исходной продукции. Как показывает практика, животноводческая деятельность в целом по региону не является продуктивной. Указанные обстоятельства аргументируют необходимость диверсификации действующих механизмов государственной поддержки развития агропромышленного комплекса, с учётом факторов, детерминирующих его эффективность. По нашему мнению, в Ростовской области нецелесообразна широкомасштабная государственная поддержка животноводства за счёт денежных средств бюджетной системы, в связи с тем, что отрицательное действие природно-климатических факторов не позволяет хозяйствующим субъектам животноводческой специализации успешно развиваться. Однако применение точечных мер господдержки, в частности, по направлению овцеводства в восточных районах Ростовской области (благоприятных для указанного направления деятельности), может дать позитивный социально-экономический эффект.

2. Вышеизложенные обстоятельства аргументируют необходимость пересмотра полномочий в сфере формирования и реализации инструментария государственной поддержки хозяйствующих субъектов АПК в части делегирования органам местного самоуправления права участвовать в разработке государственных программ стимулирования, кредитования, лизинга хозяйствующих субъектов АПК. Указанное предложение может быть реализовано посредством корректировки региональных законодательных и нормативноправовых актов, регламентирующих порядок государственного стимулирования АПК посредством формирования механизма учёта мнения муниципальных образований, заинтересованных в развитии на своей территории проектов АПК. Например, орган исполнительной власти Ростовской области, являющейся оператором реализации мер государственной поддержки Министерство сельского хозяйства и продовольствия, - может сформировать коллегиальных орган с участием представителей органов местного самоуправления аграрных районов региона для выработки наиболее эффективных инструментов государственной поддержки АПК, что позволит в максимальной степени учесть природохозяйственную специфику территорий и создать предпосылки для эффективного развития.

3. Как показывает опыт разработки инструментов государственной поддержки отраслевого развития, систематизированный в научных трудах отечественных учёных $[1,2,4]$, наиболее эффективными являются меры, разрабатываемые с участием представителей профильного делового сообщества, заинтересованного в успешных капиталовложениях. С учётом сказанного, представляется целесообразным наделения совещательных органов при региональных министерства сельского хозяйства правами нормативной инициативы, то есть подготовки нормативно-правовых актов, направленных на формирование благоприятного инвестиционного климата. По нашему мнению, реализация подобного предложения позволит значительно повысить эффективность бюджетных затрат на мероприятия господдержки агропромышленного комплекса и стимулировать инвестиционную активность в сельском хозяйстве Ростовской области. 


\section{ЛИТЕРАТУРА}

1. Брик А.Д. Об изменениях в правовом регулировании оборота земель сельскохозяйственного назначения / Брик А.Д. // Вестник Донского государственного аграрного университета. 2013. №2(8). С. 137-146.

2. Брик А.Д. Проблемы оборота земель сельскохозяйственного назначения / Брик А.Д. // Вестник Донского государственного аграрного университета. 2012. №1(3). C. 103-112.

3. Губачев В.А. Инвестиционная привлекательность и её влияние на конкурентоспособность сельского хозяйства региона / Губачев В.А. // В сборнике: Управление в условиях глобальных мировых трансформаций: экономика, политика, право Сборник научных трудов. 2017. С. 52-55.

4. Москаленко А.П. Инвестиционное проектирование: основы теории и практики Москаленко А.П., Москаленко С.А., Ревунов Р.В., Вильдяева Н.И. / СанктПетербург, 2018. (1-е, Новое)

5. Официальный сайт территориального органа Федеральной службы государственной статистики по Ростовской области http://www.donland.ru (дата обращения 15 апреля 2020 г.)

6. Плохотникова Г.В. Глобальное экономическое позиционирование Ростовской области: факторы, тенденции, направления развития / Плохотникова Г.В. // В книге: Современные проблемы управления и регулирования. Монография. Пенза, 2017. С. 104-114.

7. Плохотникова Г.В. Приоритетные направления развития конкурентных преимуществ региона (на примере Ростовской области) / Плохотникова Г.В., Дальченко Е.А. // Экономика и предпринимательство. 2018. №1 (90). С. 335-337.

8. Ревунов Р.В. Повышение эффективности экономического комплекса Юга России / Ревунов Р.В., Дальченко Е.А. // Императивы, векторы, организационноэкономические решения / Саарбрюкен, 2016.

с Брик Анна Дмитриевна (brikad@mail.ru), Плохотникова Галина Владимировна (g409zx@yandex.ru).

Журнал «Современная наука: актуальные проблемы теории и практики»

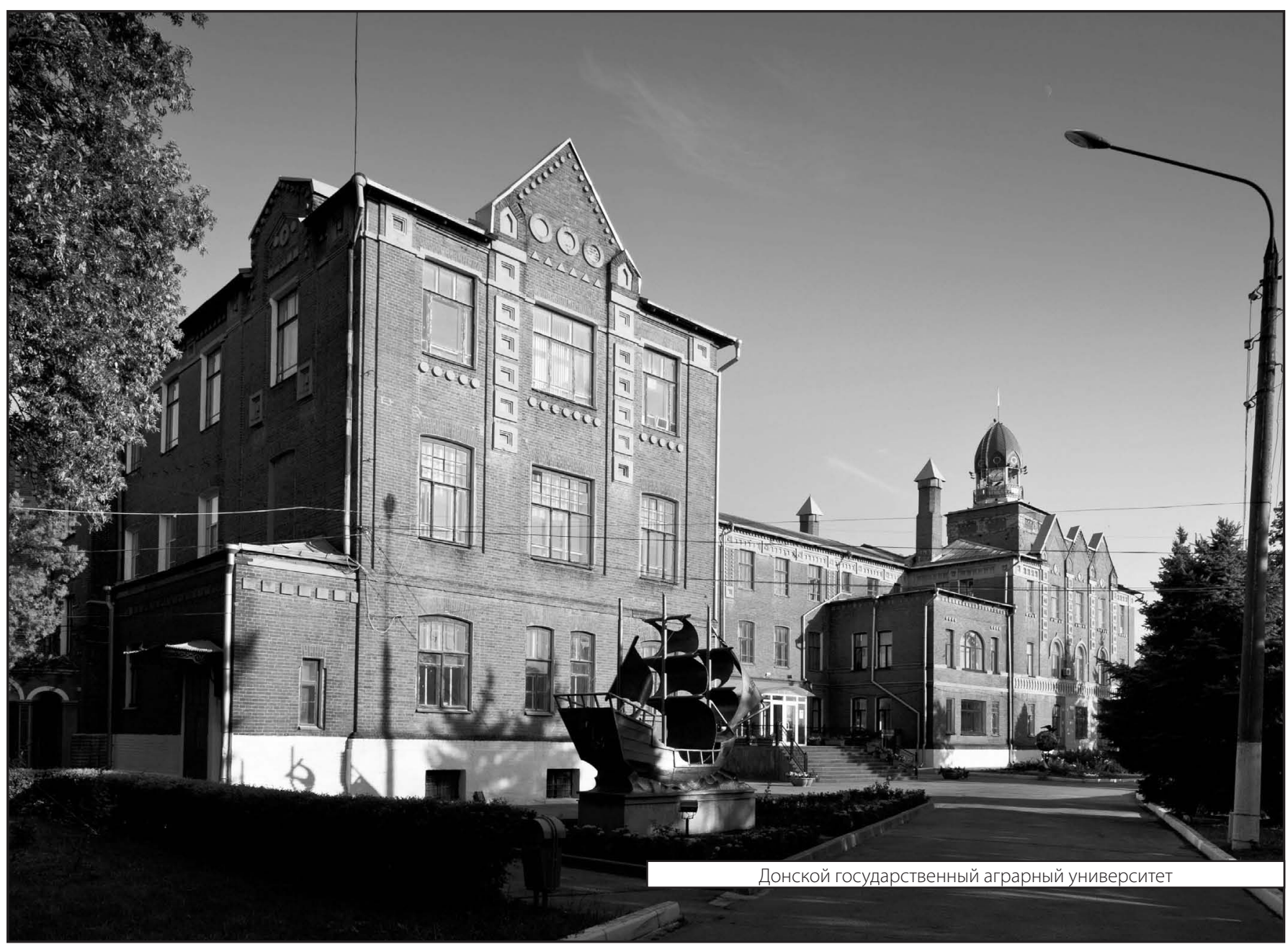

